Lenguaje creativo en el discurso periodístico deportivo. Estudio contrastivo en español, francés e inglés

\title{
Quintero Ramírez, S. (2019). Lenguaje creativo en el discurso periodístico deportivo. Estudio contrastivo en español, francés e inglés. Berlín: Peter Lang, 195 pp.
}

\author{
Nadia Valenzuela Indart \\ Universidad de Guadalajara (México) \\ nadia.vindart@outlook.com
}

\author{
Recibida: 23/06/2020 - Aprobada: 23/11/2020 - Publicada: 15/04/2021 \\ DOI: doi.org/10.17533/udea.lyl.n79a32
}

\begin{abstract}
$\mathrm{E}$ n este escrito se pretende hacer una reseña del libro Lenguaje creativo en el discurso periodístico deportivo, de Sara Quintero Ramírez, quien comienza esta enriquecedora y amena travesía por el discurso deportivo señalando, en su primer capítulo, que el periodista:
\end{abstract}

es testigo de un acontecer que arranca del pasado y se proyecta al futuro, y siendo a menudo complejo y entramado de acciones $[\ldots]$ debe decidir cómo expresar dicha complejidad de la manera más objetiva, exacta y adecuada a su audiencia (Rodríguez Castelo, 1996, p. 93).

En el primer capítulo de su libro, Quintero Ramírez manifiesta que el atractivo del discurso deportivo, el cual ha sido objeto de muchos estudios lingüísticos y literarios, es que este no es sólo más osado y libre, sino creativo al momento de informar, a diferencia de otros tipos de periodismos; como muestra de tal creatividad se encuentra el uso asiduo de figuras retóricas que muestran el estilo propio del periodista.

Tal como lo señaló la autora —ya que el deporte está presente por doquier en la sociedad —, no es de extrañarse que los medios comunicativos y digitales se vean implicados de una manera considerable, favoreciendo aun más que este sea reconocido como un fenómeno mundial, dando pie a la especialización de su discurso.

El discurso deportivo varía su expresión y forma dependiendo del medio de comunicación en el que tenga lugar. En la prensa escrita, por ejemplo, el periodista tiene el tiempo de reflexionar sobre las acciones que resultan más interesantes para su auditorio y de escogerlas con detenimiento, a diferencia de los medios orales, en los que el periodista construye su discurso de manera espontánea mientras que el evento se desarrolla y las acciones van aconteciendo. De modo que, en la prensa escrita, el periodista tiene la posibilidad de elaborar su discurso, y se da el tiempo de seleccionar los términos más adecuados y las frases más impactantes y ocurrentes.

En este trabajo, Quintero Ramírez se enfocó en analizar las figuras retóricas de orden semántico explotadas por los periodistas en notas deportivas en el marco de la prensa escrita electrónica, la cual se caracteriza por ofrecer notas más cortas que aquellas de la prensa impresa, sin mucho detalle y, sobre todo, de manera inmediata. El interés de la autora en analizar dichas figuras retóricas se debe a que son en estas expresiones en donde

Editores 
Lenguaje creativo en el discurso periodístico deportivo. Estudio contrastivo en español, francés e inglés más puede apreciarse la creatividad del periodista y el efecto que tienen en el público espectador. Así pues, la investigadora se dio a la tarea de identificar los diferentes recursos retóricos a nivel semántico que explotan los periodistas deportivos en español, inglés y francés, así como de determinar los campos semánticos a los que se recurre para establecer la permuta de significado en un contexto específico del lenguaje periodístico deportivo digital, y principalmente elucidar las funciones que despliegan estas figuras retóricas en este género discursivo.

Las figuras retóricas en las que se centró la autora son la metáfora, la metonimia y la hipérbole, las cuales presentan un cambio semántico. Se mencionará muy brevemente que la primera resulta muy recurrente en el discurso deportivo, pues no tiene que ser objetiva sino que también puede ser irreal, y tiene validez al ser la expresión de las fantasías del creador (Medina Cano, 2010, p. 198). Por su parte, la metonimia resulta muy útil para evitar repeticiones al aludir constantemente a los referentes dentro del discurso deportivo, por su naturaleza de designar una cosa mediante el nombre de otra a través de alguna relación semántica existente entre ambas; la hipérbole tiene como objetivo rebasar lo increíble y liberar la imaginación del locutor permitiéndole acudir a las exageraciones. Esta figura es frecuentemente utilizada por los periodistas para llamar la atención del receptor o para aumentar la emoción.

Luego, el capítulo II está dedicado al análisis del subcorpus en español; el III, al subcorpus en francés; y el IV, al subcorpus en inglés. Para esta investigación, se construyó un corpus total de 150 notas periodísticas deportivas y a partir de cada subcorpus se tomaron en cuenta 10 textos de la sección deportiva de cinco diferentes diarios nacionales, dando como resultado un total de 50 notas periodísticas en cada una de las tres lenguas.

Seguidamente, el capítulo v se dedica al análisis contrastado de los resultados de los tres subcorpus presentados en los capítulos precedentes. En las primeras páginas de este capítulo se muestra la frecuencia con la que cada figura se presenta en las tres lenguas, revelando que el español es la lengua que hace mayor uso de figuras retóricas. Asimismo, al interior de este primer acercamiento se puede ver que, mientras que en español y en inglés se recurre con mayor frecuencia a la metáfora, el francés privilegia el uso de la metonimia.

Ya haciendo una acercamiento al análisis contrastado de cada una de las figuras en los tres subcorpus, se analizaron, en un primer tiempo, las metáforas de los tres materiales en donde se constata tanto los tipos de metáforas como los campos semánticos a los que se recurre para su concepción; de la misma manera, se presentan los rasgos distintivos de los diarios destacados por el uso constante de esta figura. En segunda instancia, se aborda la metonimia, en cuyo apartado se mencionan los diarios que recurren mayormente al uso de esta figura y se contrastan tres aspectos principales de la misma, tales como los referentes a los que aluden, el tipo de estrategia explotada para designar al mismo y sus funciones más relevantes tanto a nivel estilístico como textual. Por último, se examinan las hipérboles, de las cuales se considera su intención comunicativa a partir de las alusiones de estudiosos de dichas figuras, así como de las propias observaciones de la autora. Al igual que con las figuras anteriores, se muestran los principales periódicos que recurren a la hipérbole, los rasgos de estos periódicos y, por supuesto, ejemplos que ilustren lo expuesto en el análisis.

De acuerdo con esta investigación, los dos tipos de metáfora más frecuentes son aquellas que recurren 
Lenguaje creativo en el discurso periodístico deportivo. Estudio contrastivo en español, francés e inglés al ámbito bélico-militar, entre las cuales se mencionan las defensivas y ofensivas de un equipo, las luchas o contiendas entre los dos equipos vistos como dos fuerzas opositoras y al modo de golpear el balón en el futbol, asociándose a la descarga de un arma; de igual modo, se exponen las metáforas orientaciones, que pueden ser ascendentes para denotar un evento positivo, como una victoria, o bien descendentes que denotan todo lo contrario, es decir, un evento negativo, como sería una derrota. Además de las anteriores, Quintero Ramírez pudo observar dentro de las metáforas estructurales los campos semánticos alusivos a la religión, la realeza, los animales, el transporte, la gastronomía — por nombrar sólo algunos_-, aunque estos últimos no resultan tan productivos como los anteriormente nombrados. Al respecto, la autora resalta que, debido a sus rasgos tanto sintácticos como semánticos, las metáforas juegan un papel muy importante en la descripción de la realidad deportiva, pues permiten conceptualizarla de manera creativa e ingeniosa y que además son las metáforas las figuras que contribuyen especialmente al embellecimiento del texto en cuestión.

De acuerdo con los materiales contenidos en los tres subcorpus, la metonimia, por su parte, se encarga de aludir a los referentes esenciales: deportistas o personajes relacionados con el deporte y equipos. En su estudio, Quintero Ramírez encontró que las metonimias empleadas para nombrar a un deportista y que coinciden en las tres lenguas son a) aquellas que mencionan un rasgo característico del mismo; b) las que mencionan la posición o función que despliega el deportista; y c) aquellas que explotan un hiperónimo que da cuenta de la profesión del referente. En cuanto a las metonimias usadas para nombrar al equipo, las estrategias más empleadas en el corpus de las tres lenguas fueron: a) el nombre del país o de la ciudad que el club deportivo representa; b) uno de los colores del uniforme; c) la condición de visitante o local en el partido que está siendo narrado; d) un sustantivo común o un sintagma preposicional que menciona al entrenador; y e) el número de deportistas que salen al terreno de juego.

En lo que respecta a las funciones estilísticas y textuales que se identificaron en los materiales analizados, se determinaron tres funciones principales en español e inglés, y dos en francés. En primer lugar, se encontró que en las tres lenguas, la metonimia despliega una función apositiva. No obstante, en español y en inglés, esta figura tiende a aparecer inmediatamente después de presentar el referente, mientras que en francés tiene también una función catafórica, apareciendo con mayor frecuencia antes de presentar el referente.

La segunda función identificada en las tres lenguas consiste en proporcionar cohesión a la nota periodística. De acuerdo con Quintero Ramírez «el periodista deportivo recurre a la diversidad de metonimias para indicar un mismo referente mediante diferentes formas, atrayendo al lector por la reacción ingeniosa del texto» (2019, p. 167).

La tercera función que pudo observarse tanto en español como en inglés, es que existe una tendencia a presentar el referente en el titular y aludir a este justo en el encabezado inferior mediante una metonimia. Dicha función, pudo observarse sólo en algunos diarios y forma parte de la función cohesionadora.

Por último, en lo que respecta a la hipérbole, se encontró que el español hace notablemente mayor uso de esta figura que las otras dos lenguas, con un porcentaje del 60,29 \% contra 16,91\% en inglés y 22,79 \% en francés 
Lenguaje creativo en el discurso periodístico deportivo. Estudio contrastivo en español, francés e inglés

(Quintero, 2019, p. 170). En su estudio, la autora observó dos tipos de hipérboles: aquellas que tienden a enaltecer personalidades deportivas y aquellas que tienden a denigrar a personalidades o equipos deportivos. De acuerdo con la autora, a pesar de que las hipérboles resultan figuras retóricas a nivel semántico menos productivas que las otras dos figuras en los materiales analizados para esta investigación, consiguen captar la atención del público lector, ocasionando incluso un momento de humor. Asimismo, señaló que las hipérboles se sirven de otras figuras retóricas como la metáfora o la metonimia, no obstante en este estudio fueron consideradas como hipérboles por sus rasgos característicos de exageración.

Para finalizar, en el último capítulo, se presentan las conclusiones tanto de los análisis de cada subcorpus como del análisis contrastado de las tres figuras en las tres lenguas. Asimismo, la autora señaló que pocos han sido los trabajos contrastados de esta índole y agregó que las aportaciones de su investigación se despliegan principalmente en tres líneas: la primera, las figuras retóricas en general; la segunda, el discurso deportivo periodístico; y la tercera, los estudios contrastivos en tres lenguas, en este caso, español, inglés y francés.

\section{Referencias bibliográficas}

1. Medina Cano, F. (2010). Los narradores deportivos y sus epopeyas coridianas. En S. Martínez (Coord.), Fútbolespectáculo, cultura y sociedad (pp. 157-207). México: Afínita.

2. Rodríguez Castello, H. (1996). El periodista y el verbo. Chasqui, 54, 93-95.

3. Quintero Ramírez, S. (2019). Lenguaje Criterio en el discurso periodístico deportivo. Estudio contrastado en español, francés e inglés. Berlin: Peter Lang. 